\title{
ANÁLISE DA INFLUÊNCIA DE BOCAIS NO ESCOAMENTO DE TANQUE EM REGIME PERMANENTE
}

\author{
D. B. de MATOS $^{1}$, A. C. MOITINHO ${ }^{1}$, M. S. ANDRADE ${ }^{1}$, W. R. S. CRUZ ${ }^{1}$ e G. F. SILVA ${ }^{1}$ \\ ${ }^{1}$ Universidade Federal de Sergipe, Departamento de Engenharia Química \\ E-mail para contato: daniellebarbosa2003@yahoo.com.br
}

\begin{abstract}
RESUMO - O esvaziamento de tanques por meio de acessórios, como os bocais, é comumente encontrado nas indústrias, sendo um dos tipos de maior aplicabilidade da mecânica dos fluidos. Bocais são tubos de pequeno comprimento, adaptados a orifícios em parede fina ou de grande espessura, utilizados no combate a incêndios, etc. O presente trabalho tem como objetivo avaliar a influência dos bocais no que diz respeito ao escoamento em um tanque em regime permanente por meio de três níveis de vazão. Confirmou-se que o jato de água se comporta com um projétil em queda livre, que a velocidade da água aumenta se aumentarmos o nível da vazão; bocais do tipo ajustado são os mais indicados quando se quer maiores alcances do jato assim como os divergentes; para médios alcances, são melhores utilizados os bocais cilíndricos e dentre estes os externos são mais indicados; a utilização de tubos de aço, dentre todos os bocais estudados, acarreta em menores alcances do jato e supostamente maior tempo de escoamento.
\end{abstract}

\section{INTRODUÇÃO}

O escoamento de líquidos por meio de acessórios acoplados nas tubulações é comumente encontrado nas indústrias, sendo um dos tipos de maior aplicabilidade da mecânica dos fluidos. $\mathrm{O}$ conhecimento acerca dos fenômenos físicos que possam estar envolvidos é de suma importância para se obter informações de como se comportará o fluido dentro de tanques quando o nível do mesmo é mantido constante.

Dentre estes acessórios, estão os bocais que são tubos de pequeno comprimento, adaptados a orifícios em parede fina ou de grande espessura, utilizados no combate a incêndios, operações de limpeza, serviços de construção, máquinas hidráulicas,etc.

Com o intuito de se verificar o esvaziamento de tanques e vazões em massa, dispositivos foram desenvolvidos, por meio da equação de Bernoulli (MUNSON, 2013) e sua escolha depende, em grande parte, do tipo de tanque que transporta o fluxo (GRIBBIN, 2009). Tal equação advém dos princípios das conservações de massa e energia e é de suma importância para verificar a velocidade que seria ideal em determinado escoamento à nível constante. 
Porém, sabe-se que nos escoamentos reais, em sua grande maioria turbulentos, os fluidos possuem viscosidade e, com isso, há perda de carga distribuída ocasionada pelo efeito do atrito no escoamento completamente desenvolvido em tubos com diâmetro constante, além da perda de carga localizada, provocada por acessórios acoplados nos tubos ou tanques de esvaziamento.

No tocante à perda de carga, esta vai depender da geometria, disposição e dimensões do bocal. Os bocais são geralmente cilíndricos ou cônicos, salientes ou reentrantes.

\subsection{BOCAIS}

São tubos de pequeno comprimento, adaptados a orifícios em parede fina ou de grande espessura, utilizados no combate a incêndios, operações de limpeza, serviços de construção, máquinas hidráulicas, etc. (AZEVEDO, 1998). As equações utilizadas para orifícios pequenos, descritas anteriormente, são válidas também para os bocais. No tocante aos valores dos referentes coeficientes e na perda de carga, estes vão depender da geometria, disposição e dimensões do bocal. Os bocais são geralmente cilíndricos ou cônicos, salientes ou reentrantes. A seguir, encontram-se os tipos de bocais.

\subsubsection{Bocal Ajustado}

A forma deste tipo de bocal é adaptada ao formato do jato que sai de um orifício, de modo que não há praticamente contração ocorrida no mesmo, ocasionando perda de carga mínima, sendo por isso o mais apropriado a ser utilizado nas saídas de reservatórios.

\subsubsection{Bocal Cilíndrico Externo}

Este tipo de bocal se projeta para fora da parede do tanque, possui forma cilíndrica e seu comprimento está em torno de 1,5 a 3 vezes do valor de seu diâmetro; ocasiona veia líquida contraída, a partir do qual o jato se expande e que, na saída do bocal, enche-o completamente.

\subsubsection{Bocal Cilíndrico Reentrante ou Interno}

Como o próprio nome já diz, possui formato cilíndrico e se projeta para o interior da parede do tanque; o jato sofre contração na entrada do bocal e não toca nas paredes internas do mesmo, caso seu comprimento estiver em torno de 0,5 a 1 do diâmetro da seção de saída.

\subsubsection{Bocal cônico convergente}

Se a entrada do bocal possuir bordos agudos, haverá uma mínima contração do jato , alterando-se de acordo com o ângulo de convergência e do seu comprimento. 


\subsubsection{Bocal cônico divergente}

Caso a entrada do bocal possua bordos agudos e ângulo de divergência pequeno (em torno de $15^{\circ}$ ), a turbulência, perda de carga e contração do jato serão mínimas, sendo a velocidade de saída do bocal próxima a da ideal.

\section{METODOLOGIA}

Os experimentos deste estudo foram realizados no Laboratório de Fenômenos de Transportes (LFT) do Departamento de Engenharia Química da Universidade Federal de Sergipe. Três alturas do reservatório com nível ajustado foram fixados: 0,3 m (nível baixo), 0,6 m (nível médio) e $0,9 \mathrm{~m}$ (nível alto). Em seguida, encheu-se o reservatório com água. O primeiro bocal a ser estudado foi enroscado na saída do tanque de descarga e, após a verificação da válvula VB3 fechada e da VB2 aberta, ligou-se a bomba centrífuga através do painel eletrônico. Feito isto, abriu-se a válvula VR1 para que o fluxo de água subisse para o tanque. Para nivelar a vazão, as válvulas situadas no tanque eram abertas, assim como a válvula VR2. Percebido o nível de água constante na posição desejada, procedeu-se a leitura de seis posições (X e Y), em triplicata, do jato de água que saía através do bocal, utilizando-se a régua cartesiana móvel. Para um completo esgotamento do tanque de descarga, fechou-se a VR1 e abriram-se as válvulas VR2 e VB3. Utilizando o paquímetro, os valores dos diâmetros bem como o valor do comprimento de cada bocal foram medidos. Abaixo, encontra-se o esquema do aparato experimental.

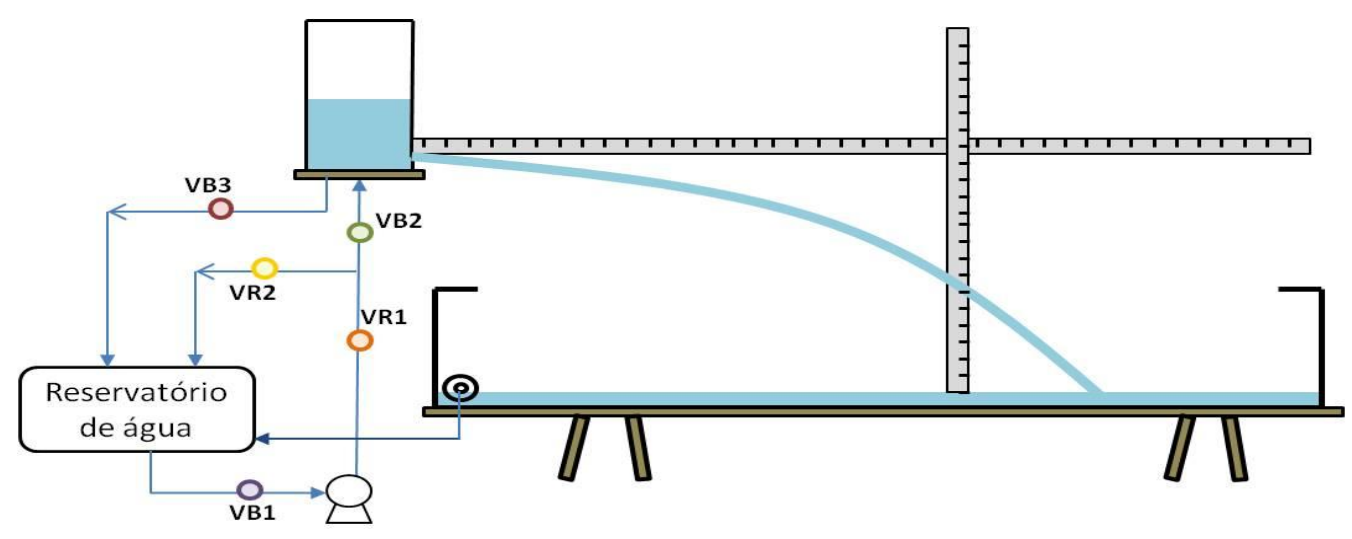

Figura 1- Esquema do aparato experimental e os sentidos dos fluxos de água. 
A seguir, encontram-se as figuras dos bocais estudados:

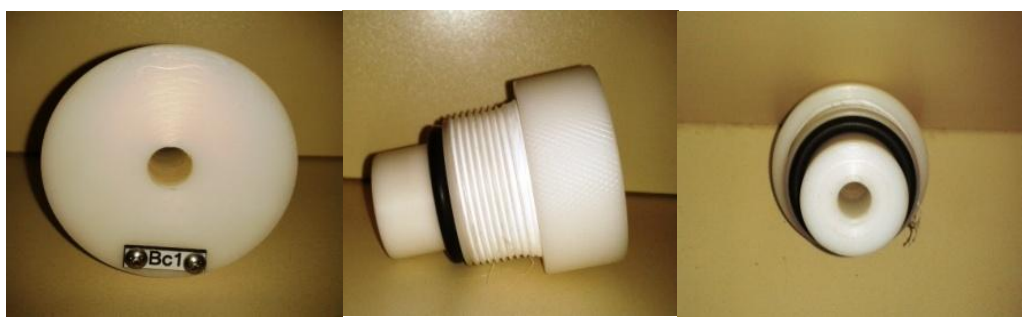

Figura 2- Bocal cilíndrico externo BC1.

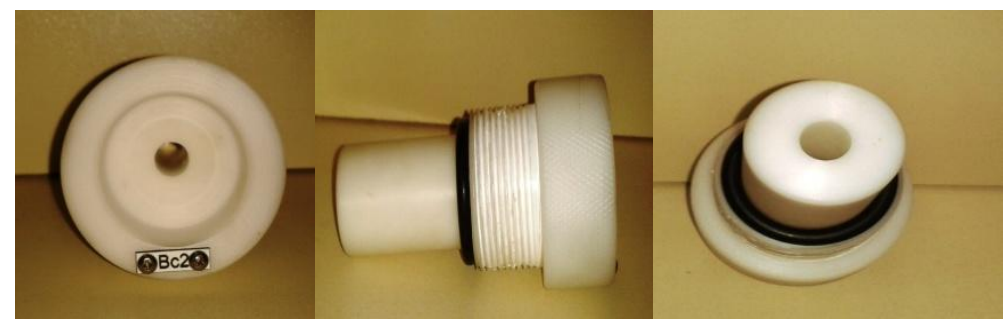

Figura 3- Bocal cilíndrico interno BC2.

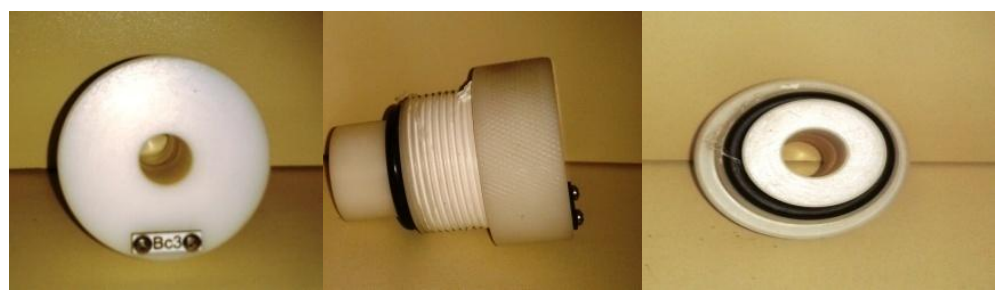

Figura 4- Bocal cilíndrico externo BC3.

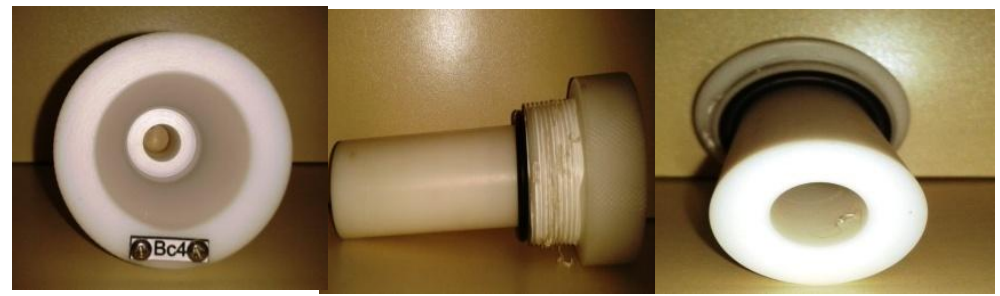

Figura 5- Bocal cilíndrico interno BC4. 


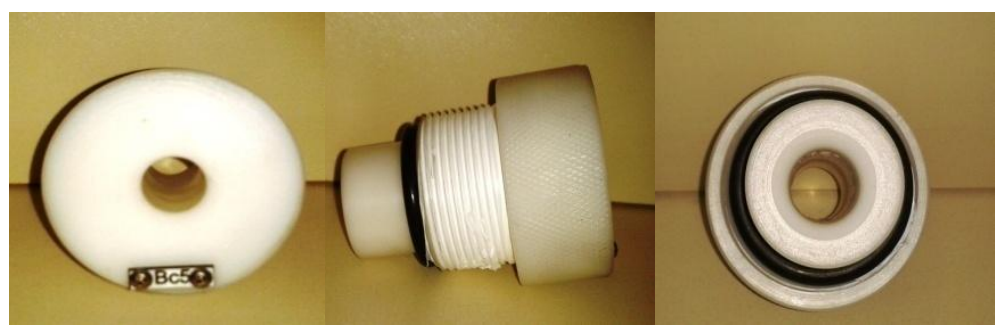

Figura 6- Bocal cilíndrico externo BC5.

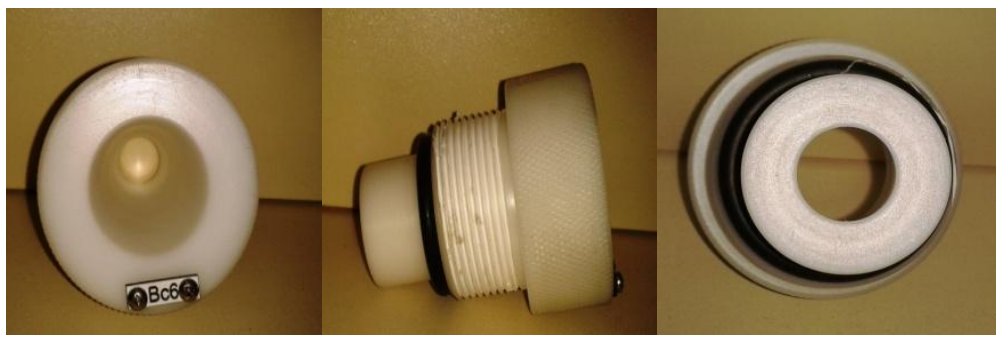

Figura 7- Bocal cônico divergente BC6.

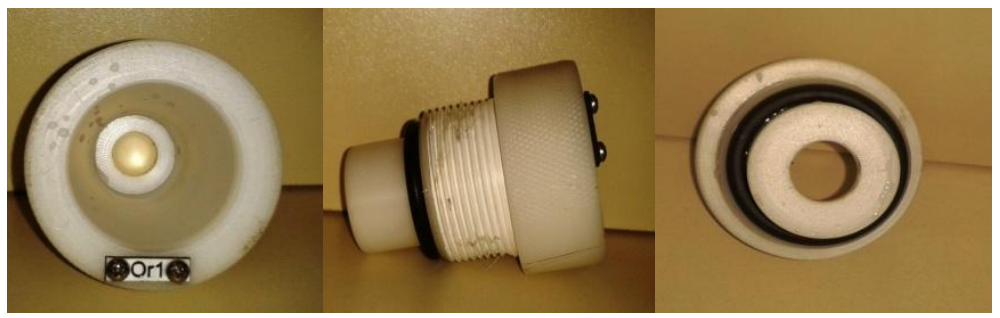

Figura 8- Bocal ajustado OR1.

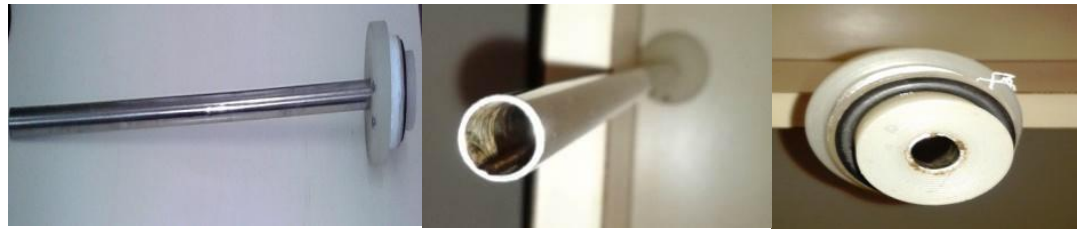

Figura 9- Bocal constituído em tubo de aço (TA). 


\section{RESULTADOS E DISCUSSÕES}

De posse dos valores medidos em triplicata para cada nível e bocal, foram construídas as curvas da trajetória do jato por meio do ajuste matemático polinomial e, a partir da análise das melhores curvas, fez-se uma média dos valores para, então, ter-se a construção dos gráficos contendo os três níveis estudados, apresentados nas Figuras 10 a 13:

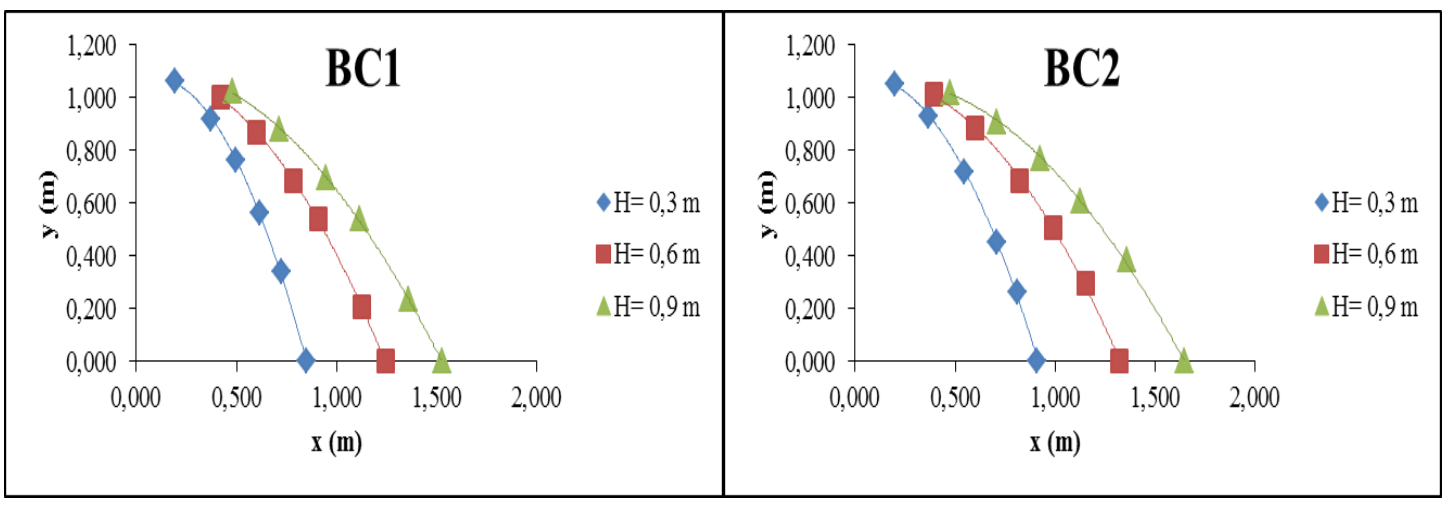

Figura 10- Trajeto do jato de água nos três níveis para o bocal BC1 e BC2.

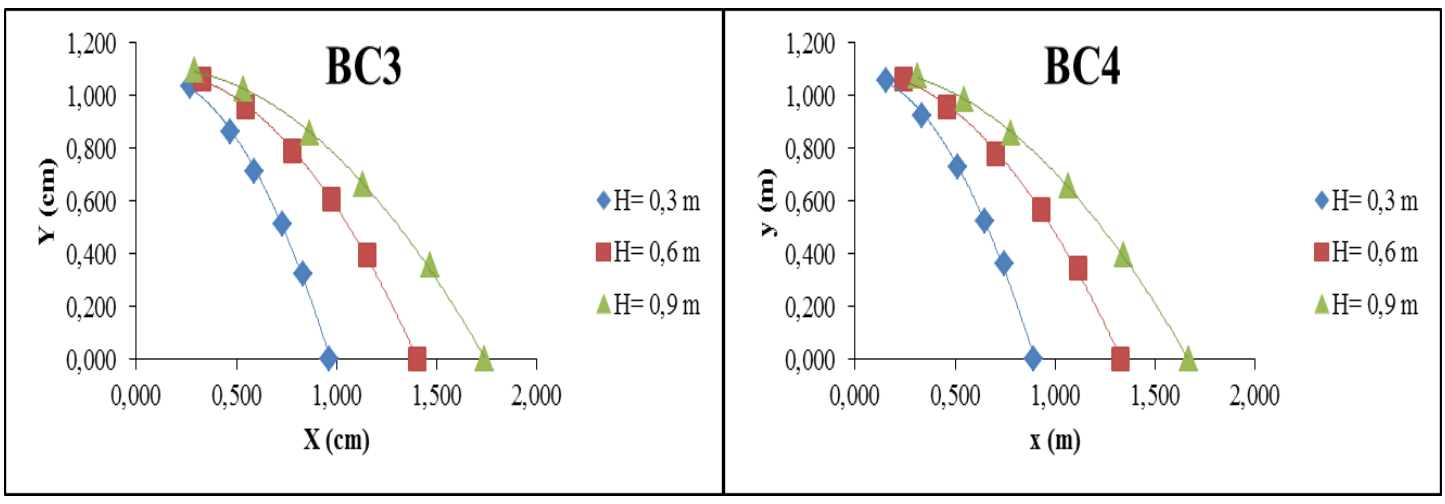

Figura 11- Trajeto do jato de água nos três níveis para o bocal BC3 e BC4. 


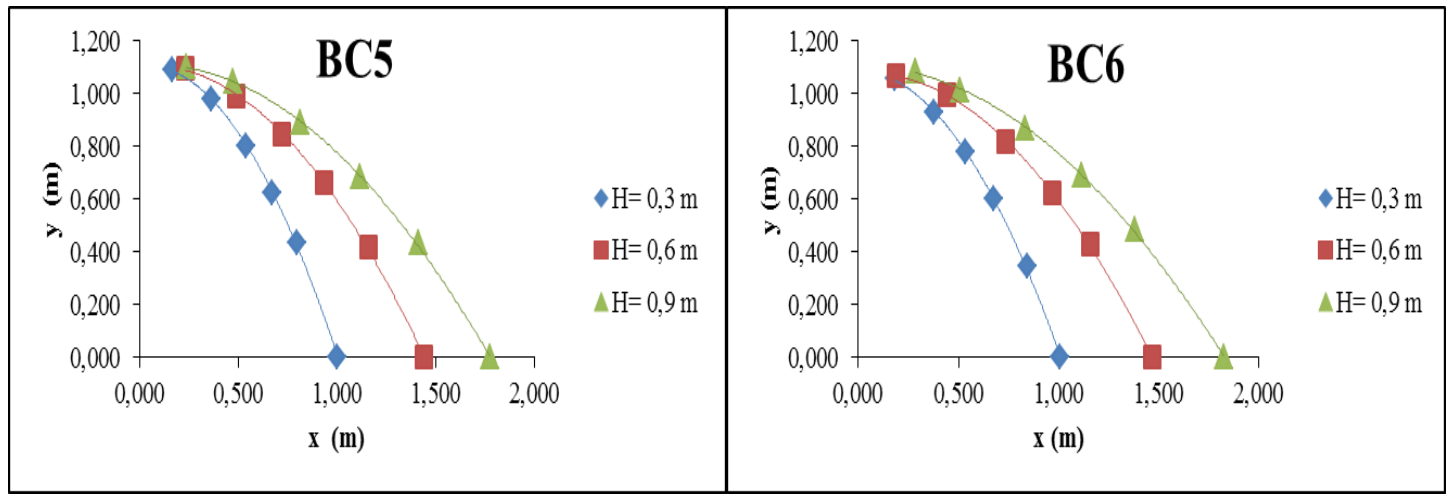

Figura 12- Trajeto do jato de água nos três níveis para o bocal BC5 e BC6.

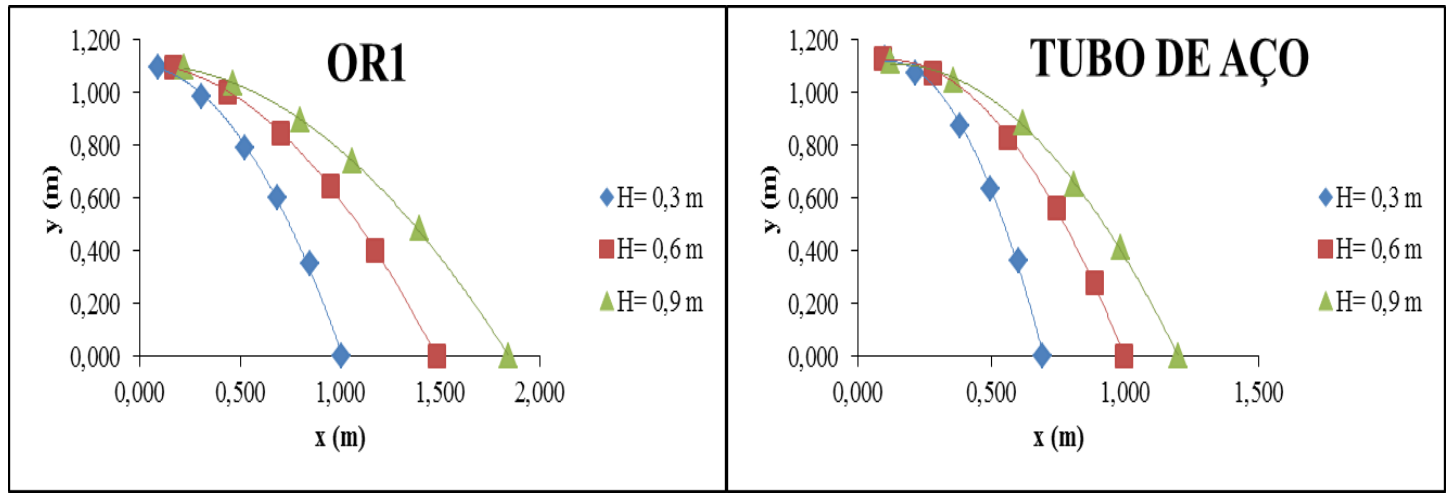

Figura 13- Trajeto do jato de água nos três níveis para o bocal OR1 e do TA.

Observando os gráficos acima, percebemos que à medida que se aumenta o nível de água o alcance do jato é maior, como esperado já que a energia potencial aumenta e, consequentemente, há maior velocidade de saída. O elevado alcance do jato quando se usa o bocal ajustado OR1 se deve ao fato de reduzir qualquer perturbação ao fluido já que ele está rente à parede e sem protuberância, o que ocasionaria em aumento de perda de carga. Percebemos que os menores alcances ocorre quando se usa o tubo de aço, isto ocorre devido a altas perdas de carga presente no mesmo. Entre os bocais cilíndricos externos, percebemos maiores alcances do jato quando é utilizado o BC5 e entre os internos, o bocal BC4.

Dentre os bocais, o que possui menores alcances nos três níveis é o tubo de aço, uma vez que este possui o maior comprimento e, com isso, maior perda de carga distribuída. Já o bocal que possui maiores alcances é o ajustado OR1, o que era esperado, pois ocorre uma redução na área de escoamento e, portanto, um aumento da velocidade. Em seguida, notamos maiores 
alcances quando utilizado o bocal divergente BC6. Com relação aos bocais cilíndricos, percebemos que o externo BC5 e o interno BC4 possuem os maiores alcances.

\section{CONCLUSÕES}

Bocais do tipo ajustado são os melhores indicados quando queremos um maior alcance do jato que, supostamente, terá menor tempo de esvaziamento do tanque assim como os divergentes, porém estes originam maiores turbulências e perdas de carga.

Para médios alcances, são melhores utilizados os bocais cilíndricos e dentre estes os externos são mais indicados por possuírem menores perdas de carga e que o esvaziamento através de tubos de aço, dentre todos os bocais estudados, é o acarreta em menores alcances do jato devido à força de arraste através de suas paredes que aumenta a queda de pressão e, consequentemente, menor energia cinética terá o fluido.

\section{REFERÊNCIAS}

AZEVEDO, J. M. N.; FERNANDEZ, M. F.; ITO. Manual de Hidráulica, $8^{\text {a }}$ Ed., São Paulo: Editora Blucher, p. 66, 1998.

GRIBBIN, J. E. Introdução à Hidráulica, Hidrologia e Gestão de Águas Pluviais. São Paulo: Cengage Learning, $3^{\mathrm{a}}$ Ed., 2009.

MUNSON, B. R.; YOUNG, D. F.; OKIISHI, T. H. Fundamentos da Mecânica dos Fluidos. São Paulo: Blucher, $1^{\mathrm{a}}$ Ed., $4^{\mathrm{a}}$ Reimp., 2013. 